\title{
Value Co-creation and Co-innovation: Linking Networked Organisations and Customer Communities
}

\author{
David Romero and Arturo Molina \\ Tecnológico de Monterrey, Campus Monterrey \& Ciudad de México, México \\ david.romero.diaz@gmail.com, armolina@itesm.mx
}

\begin{abstract}
Strategic networks such as Collaborative Networked Organisations (CNOs) and Virtual Customer Communities (VCCs) show a high potential as drivers of value co-creation and collaborative innovation in today's Networking Era. Both look at the network structures as a source of jointly value creation and open innovation through access to new skills, knowledge, markets and technologies by sharing risk and integrating complementary competencies. This collaborative endeavour has proven to be able to enhance the adaptability and flexibility of CNOs and VCCs value creating systems in order to react in response to external drivers such as collaborative (business) opportunities. This paper presents a reference framework for creating interface networks, also known as 'experience-centric networks', as enablers for linking networked organisations and customer communities in order to support the establishment of user-driven and collaborative innovation networks.
\end{abstract}

Keywords: Collaborative Networked Organisation, Customer Communities, Value Co-creation, Co-Innovation, Open Innovation, User-Driven Innovation.

\section{Introduction}

In today's global economy, organisations are collaborating more and more, thus organisations are engaging in new forms of highly collaborative mechanisms and networked structures capable of providing a competitive advantage by combining the best skills or core competencies and resources of two or more organisations, plus customer knowledge regarding a product (good or service) to co-create a value proposition more compelling and relevant for the consumers' needs and expectations.

In this sense, collaborative networks represent a promising paradigm together with customer communities to emphasis on core competencies, personalisation and innovation, supported by collaborative mechanisms, in order to allow the consumer to stamp a product with his/her own applications, preferences and configurations, and therefore co-create value in a collaborative endeavour.

Collaborative Networked Organisations (CNOs) show a high potential as drivers of value co-creation, allowing organisations to access new knowledge, sharing risk and resources, joining complementary skills and capacities, which allow them to focus on their core competencies. In addition, CNOs induce innovation and thus cocreate new sources of value by confrontation of ideas and practices, combination of resources and technologies, and creation of synergies [1]. 
On the other hand, Virtual Customer Communities (VCCs) show a promising (business) value as "social networks" capable of leveraging all aspects of a product, from product design and marketing communication to creating the overall brand experience. VCCs can support mass-customisation strategies by allowing customers to become co-designers of their own products [2]; sales and marketing initiatives through viral marketing strategies [3]; and branding strategies through connecting customers around the lifestyles associated with their products [4].

In this context, CNOs working together with VCCs can be seen as a cooperative process of value co-creation and open innovation, through which a group of entities enhance the capabilities of each other by sharing risk, resources, responsibilities and rewards to co-produce a unique value proposition for each consumer and stakeholder.

\section{An Experience-Centric Network Reference Framework}

Conventional ways of gaining competitive advantages like cost, quality and responsetime will not go away, but in order to compete successfully in the future companies will require building new capabilities to co-create value through experiences ${ }^{1}$ together with their customers, rather than based-on the traditional product-centric approach [5]. Building new capabilities to compete in the future implies the design and development of innovative experience environments supported by collaboration ICT-infrastructures enabling the interaction between customers' communities and networked organisations, which allows the co-creation of value, and therefore shifts the bases of competition from products to experiences.

Creating experience-centric networks (interface networks) ${ }^{2}$ requires crafting highly interactive and collaborative experience environments (e-platforms), and multiple experience gateways (interfaces), that work as communication spaces and channels for firm-customer interaction, allowing the consumer to shape his/her own personal experiences in a ubiquitous context in a fast, simple, opportune and secure way.

Following paragraphs will depict a reference framework as a synthetic structure of guidelines for describing a set of concepts, methods and technologies necessary for creating successful experience-centric networks and their supporting experience environments (see Fig. 1).

\subsection{Value Co-creation Strategy Definition}

Strategy helps organisations to be prepared for competing in the future. A strategy definition allows organisations to identify new opportunities to bring value to their customers and stakeholders.

A value co-creation strategy refers to the description of the manner in which a network of organisations intents to gain competitive advantage by involving their customers and business allies in a jointly value creation process.

\footnotetext{
${ }^{1}$ Experience(s) - Interactions between customer and producer for personalizing/shaping a product (good or service) based upon the customer's specific needs and situations (e.g. context).

${ }^{2}$ Interface Network - A meta-network compromising a network of enterprises (designers, manufactures, brokers, etc.) merged with a network of (lead) customers, which is supported by an adequate collaboration platform and infrastructure, creating a synergetic innovation ecosystem.
} 


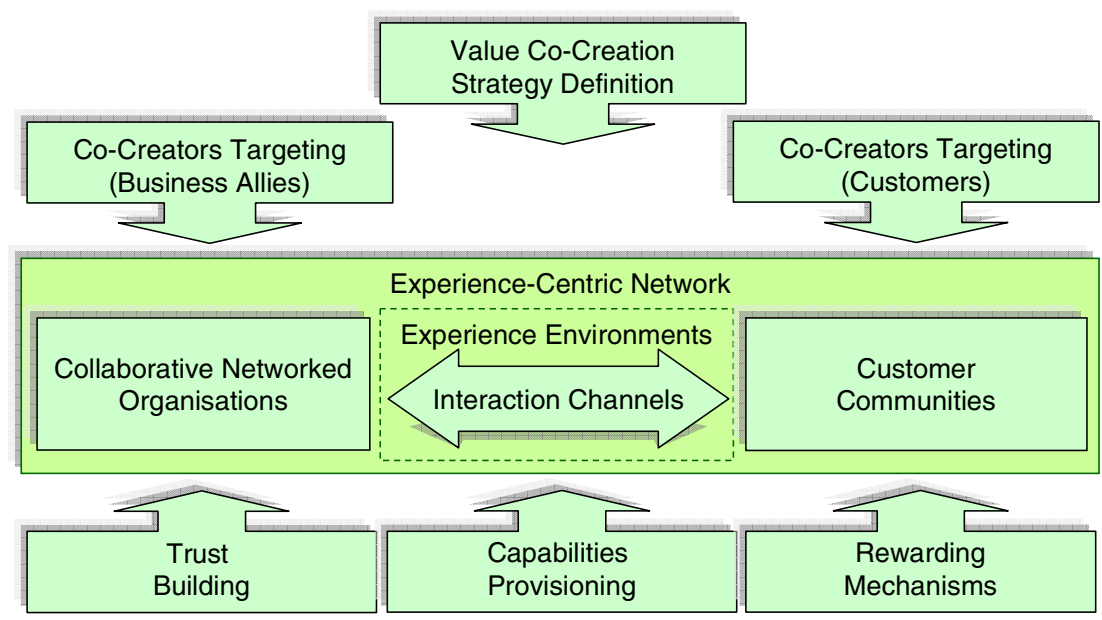

Fig. 1. Experience-Centric Network Reference Framework

A value co-creation strategy describes the actions aimed at configuring a value creation system as a set of people, organisations and technology acting as a symbiotic business ecosystem in which organisations and customers interact in dynamic and reciprocal relations towards their commitment in the process of co-producing value offerings: goods, services and experiences, in a mutually beneficial producercustomer relationship [6].

Furthermore, a strategy is adaptable by nature rather than a rigid set of instructions of how creating value for a target market. Hence, business models as definers of the value creation priorities in an organisation should be continuously reviewed in response to actual and possible changes in the perceived market conditions and evolve the enterprise strategy as the business environment and customers' needs change.

In value co-creation context, strategies and business models are continuously shaped over time in a discovering process of new sources of value and new opportunities and ways for co-creating it by/for the customers and stakeholders in the short- and long-term. Therefore, strategy definition will be a process of continuous discovery, active learning and adaptation within an agile business ecosystem capable of accessing new competencies, rapidly re-allocating resources and leveraging the organisational capabilities and capacities to compete based-on experiences.

\subsection{Co-creators Targeting}

Selecting the right criteria to target the right co-creators is a major task in the process of constructing effective co-creation partnerships with customers and business allies. Therefore, when selecting the most suitable co-creators two things are important to bear in mind: Not all customers can be good co-creators. This role depends on their complementary competencies understood as their knowledge, skills, expertise and behaviours in the experience co-creation domain, plus their enthusiastic attitudes to enhance existing product to match customers' requirements or co-create new ones that will serve to the new consumers' necessities. Furthermore, not all business allies can 
be good co-creators. This role also depends on the organisations' complementary competencies understood as their processes capabilities and resources capacities that are required to co-produce a product that serve as recipients to deliver co-creation experiences.

Some aspects to keep in mind when targeting the right co-creators include defining the kind of partnership to be established, making clear its aims as a set of common interests and understandings of the joint goals and the requirements for working together in a trustable cognitive, normative and affective collaborative environment based-on dialogue and common values to integrate complementary expertises to cocreate value [7].

After targeting the right co-creators, then is time to obtain their commitment to act jointly to co-create value in a collaboration (business) opportunity. The next two elements of the reference framework will focus on this challenge by suggesting CNOs creation as dynamic organisational forms able to rapidly establish and adapt to the changing market conditions such as customers' needs and preferences [1] [8]; and the CCs creation as experience sharing and users communities aimed to inform and allow consumers to discuss about the quality and drawbacks of products prior to making a purchase, and after the purchase is made, help them to use at best their products by making them aware of all their potentialities and if necessary assisting them to solve their problems [9].

\subsection{Collaborative Networked Organisation Creation}

In today's society, value creation has become far more dependent on intangibles such as knowledge, relationships and branding, and very soon on experiences. Thus, characteristics such as flexibility, agility and adaptability have become the new key success factors to deliver customer value, which has also become increasingly complex, dynamic, and dependent upon consumers' expectations. Therefore, the possibility of rapidly configuring a group of organisations into a goal-oriented network, like the classical 'Virtual Organisation', triggered by a value co-creation opportunity and specially tailored to satisfy the customer's specific requirements it is frequently mentioned as an expression of agility in customer value delivery.

Virtual Organisations (VOs) represent temporary alliances of organisations driven by the objective of grasping a single collaboration opportunity and dissolve once their mission/goal has been accomplished. Its temporary nature has proven to better fit with the market dynamics and the variable duration of today's business opportunities, and its VO partners' competencies integration approach to better respond to the customers' specific needs and requirements [8].

Nevertheless, the effective creation of truly dynamic VOs, which are appropriate for catching-up with customers' continuously changing preferences, since customer value is contextual, requires the pre-existence of suitable VO Breeding Environments (VBEs) meant for preparing organisations to rapidly get involved in collaboration opportunity-based VOs [8].

Once a collaborative network has the conditions provided by a VBE to support the rapid and fluid configuration of VOs when a co-creation opportunity arises, the possibility of creating or redesigning a value creation system on-demand as a co-operative venture among business allies will emerge from the breeding environment with the 
capability and capacity to address each co-creation opportunity with a tailored value creation system that fits exactly with the customer specific requirements. In this sense, each co-creation opportunity will denote a $V O$ creation process with its corresponding custom-made value creation system within a VBE, integrating the skills or core competencies and resources of the business allies (VO partners) involved for adequately supporting a co-creation opportunity together with the customer involvement and its specific needs. Under these conditions and according to the VO lifecycle (creation/operation/dissolution) each value creation system will be organisationally and technically integrated to co-create value for a specific customer and just for the period of existence of the co-creation opportunity which is being responded at the moment [10] [8].

The possibility of systematically integrating VO partners' skills and resources in a short-term coalition to serve to the customers' specific requirements represents a new source of sustainable competitive advantage in a changing global market of evolving and emerging customer needs.

\subsection{Customer Communities Creation}

Promoting the creation of Virtual Customer Communities (VCCs) provides companies with new interaction channels to co-create value through customer relationship management, by incorporating enthusiastic consumers that would be difficult to reach without the support of information and communities technologies [11].

VCCs represent valuable forums in which products, plus customer service, can be discussed, analysed, criticized and potentially improved. VCCs stand for real living laboratories in where multiple users (consumers) of the same or different products can come together to discuss the quality and satisfaction level of their current products, or comment about ideas for new ones, outside of the commercial negotiation. The social interaction among customers in this kind of virtual communities represents potentially insightful information, and a great possibility to foster companies' inter-relationships with their consumers [12].

10 best practices for building and facilitating VCCs according to Communispace Corporation [13] are: (1) Invite the right customers, keep the communities private and small, and categorize customers to uncover interests, passions and willingness to participate - avoiding using simply demographic criteria; (2) View community members as advisors to the company, not as a market research panel; (3) Find the social glue by focusing on topics of shared interest and relevance for the community, rather on just company's interests; (4) Work at building the community by creating activities (e.g. rituals/traditions) that help customers to feel comfortable in participating; (5) Be a genuine, open and encourage community's facilitator by reinforcing proactive behaviour; (6) "Just plain ask", the best way is to just ask, simply and straight-forwardly; (7) Pay even more attention to what members initiate, the best insights often come from discussions started by members - "listen more than ask"; (8) Don't squelch the negative, the best lessons come from hearing about those things that annoy, disappoint or outrage customers, so encourage members to give the good, bad and the ugly; (9) Don't ask members for too much too often or they will become fatigued; and (10) Make sure the community is built on multiple underlying technologies and methodologies so that 
people aren't stuck just answering surveys or posting to message boards (e.g. livechats, visual profiles, upload advertisements, video-diaries, etc.).

Furthermore, VCCs represent part of the knowledge revolution in where vast complement of knowledge and understanding can be tapped from customers, and combined with skilled and experienced knowledge workers (e.g. engineers as co-creators) in a greater customer intimacy and synergetic win-win situations (e.g. co-creation opportunities) to improve products by collaborating in a jointly value creation process to co-create products specially tailored to fit customers' desires. Therefore, any company capable of creating and sustaining customer communities related to its products and overall marketing strategy can expect to drive higher revenues, deeper customer loyalty and a real competitive advantage in today's economy [12].

Managing value co-creation in customer communities remains as one of the key research areas requiring that value managers, on both consumer and producer sides, understand the value co-creation strategies that drive, sustain and support experience environments, and thus comprehend which are the process and competencies that customers employ to render value according to its necessities, so companies will be able to create the capabilities to support those value co-creation processes in experience-centric networks [14].

\subsection{Trust Building}

Stability and success of experience-centric networks requires the right balance of trust among organisations and customers [15]. Trust is the glue that holds and links organisations and customers together, making possible the process of value co-creation. Trust is the atmosphere and the medium in which customers and organisations are dialoguing. It is also the base of cooperation among customers and organisations, and it is the main requirement in experience-centric networks in order for them to exist [16]. Thus, trust represents a bilateral process that requires mutual commitment between organisations and customers when attempting to keep their promises (e.g. building credibility). Some strategies identified by Jarvenpaa et al [17] suggest that trust building in virtual environments can be facilitated with: (1) proactive style of actions, (2) work-focused interactions, (3) optimistic team-spirit, (4) dynamic leadership, clear roles and objectives, (5) frequent interactions, and (6) immediate feedback. Hence, trust in virtual environments relies on virtual interaction and meeting to commitments.

In the co-creation paradigm, trust building can be supported through Prahalad's \& Ramaswamy's [5] [18] DART building blocks: Dialogue, Access, Risk-assessment and Transparency. Therefore, in a value co-creation process it is clear that engaging customers directly in the co-creation of value involves risks for both, customer and producer, so keeping this in mind dialogue will be the element that encourages not just knowledge sharing, but even more importantly, shared understanding between companies' and customers' concerns. Additionally, dialogue also gives consumers an opportunity to interject their view of the outcomes of value into the process of value co-creation. Moreover, giving customers access to knowledge, tools and expertise helps them to construct their own experience outcomes, and this also challenges the notion that ownership is the only way for consumers to experience value by focusing on access to experiences at multiple experience gateways (interaction points), as opposed to mere ownership. Furthermore, since risks are involved for both sides, risk 
assessment assumes that if consumers become co-creators of value, they will demand more information about potential risks related to product developments, but they will also have to bear more responsibility for dealing with those risks. Thus, transparency of information in the interaction processes will be necessary for customers to participate effectively in a co-creation mode, and to build trust between organisations and consumers.

DART building blocks must be enabled by technical and social infrastructures (e.g. e-platforms \& virtual communities) that allow consumers to co-create experiences they value and represent business value for organisations.

\subsection{Interaction Channels Building}

Experience gateways represent the creation of multiple customer interaction channels (e.g. Web-based and traditional ones), including experience rooms (e.g. sand-boxes) ${ }^{3}$, aimed at providing consumers with an end-to-end experience across all the systems, people and organisations in a value network, and through all interaction points (channels) that a customer uses to create and shape his/her own personal experiences with their product providers by having access to a co-creation toolkit [19] to construct their own experience outcomes by co-design and co-developing their own products. Moreover, it is important to recall at this point that 'value co-creation' is contextual, and therefore customers' interactions are the key essentials in the value co-creation process with their product providers.

Furthermore, supporting multiple interaction channels, and at the same time avoid losing customers' value co-creation context when they move from one interaction channel to another, will require a new generation of customer contact centers (e.g. call-centers, help-desks) known as customer interaction hubs capable of processing distributed and heterogeneous sources of information, regardless of the multiple communication channels available to manage a customer unified and contextual profile to deliver a unique customer experiences of value [20].

Customer interaction hubs are emerging ICT-infrastructures able to support customer interactions across multiple channels and provide a uniform response to the customers demands at any point of the value co-creation process; allowing organisations to choose the right approach and method for responding to a customer requirement based-on a common view of his/her experience context. The end-result will be the right response with the right information to the customer, achieving a higher customer satisfaction level [20].

Some recommendations when building and managing customer interaction channels are: (1) Provide multiple interaction channels to the customers to allow them to choose which channels are more convenient for them in order to participate in different value co-creation processes; (2) Design each experience gateway considering the DART building blocks; (3) Manage experience quality management across all interaction channels - "it is about an integral experience"; (4) Ensure best practices to standardize the quality of customer service across all interaction channels and cocreator agents; (5) Enable intelligent cross-communication to turn the customer hub

${ }^{3}$ Experience Room - An interactive environment where customers "play" with products and shape them. 
into a real experience environment; and (6) Consider multiple customers' choices from a simple transaction process (e.g. a purchase) to the overall co-creation experience through the interactive personalization of products [5] [18] [20].

One question that could arise when building interaction channels for the customers is where should an organisation create these experience gateways, and a possible response to this strategic question is suggested by Ramaswamy \& Gouillart [21], who recommend the use of "interaction maps" aimed at discovering key interaction points where companies can devise new or better interactions for improving dialogue, access to knowledge, mutual understanding of risks and transparency in the value co-creation process with their customers. These interaction maps can be represented in a formal way by using UML 2.0 interactive diagrams such as a sequence diagram displaying the time sequence of the entities participating in an interactive process, or even better, a collaboration diagram displaying an interaction process organised around the entities and their links to each another. Using this kind of UML interactive diagrams, organisations may capture the behaviour of a single co-creation use case by visualizing the collaboration between entities in a value creation system to accomplish their value co-creation goal.

Another formal approach to map firm-customer interactions could be through a Business Process Modelling (BPM) approach as a way of providing organisations with the capability to understand their interactive/collaborative business processes in a graphical notation and comprehend better the organisational collaborative performance in each co-creation process with the customers and business allies.

Other possibility could be the use of simple cross-functional diagrams that can also serve to the process of mapping firm-customer interactions.

Experience environments will require the integration of multiple experience gateways as enablers of customer interaction with the node organisation and its network to co-create unique and personalized experiences of value [5].

\subsection{Capabilities Provisioning}

An experience-centric network can be understood as a solution generator capable of associating organisations core competencies and resources into collaborative networks on one side, and on the other side collect enough consumers' knowledge from customer communities to understand how to satisfy the personal consumers' requirements. Therefore, CNOs and CCs creation represent one of the most suitable ways for providing a group of organisations and consumers with the right capabilities and training to efficiently co-create value within experience environments.

CNOs allow the integration of organisations in networked structures (e.g. VOs) that represent tailored on-demand value creation systems with the capabilities to adapt and rapidly reconfigure resources and accommodate them to satisfy the consumers' demands within experience environments, which can deliver personalized products that complain with customers' specific needs.

Properly designed value creation systems will allow CNOs to perform value cocreation processes for satisfying consumers' specific requirements in a fast and efficient way thanks to the advantages and benefits of collaboration.

On the other hand, $\mathrm{CCs}$ can provide organisations with the information to recognize with enough time which will be the new required capabilities to satisfy consumers' 
needs and aspirations in the near future, so networked organisations (e.g. a VBE) can recruit new business allies that can contribute to the emergence of new competencies to support proactive interaction between consumers and producers in the conjoined personalization of products.

By integrating CNOs and CCs into experience-centric networks, both entities will be able to actively select the competencies required for co-creating personalized experiences in experience environments. These, with the technical and social infrastructures to align different business and consumer value co-creation processes with the agility and flexibility required to capture the time frame of co-creation opportunities (e.g. collaboration // business // opportunity).

Lastly, sustainable competitive advantages and business success in the emerging experience economy will depend on organisational networks capability to speed-up, innovate and focus on core competencies of their business allies to meet the consumers' specific requirements and demands, capture new markets and beat the competition by creating unique experiences with profitable business grow.

Furthermore, value will no longer be developed inside organisations, but from the interaction with consumers and business allies in experience gateways, allowing the co-design and delivering of personalized products. Thus, innovation and commercialization of technologies, goods and services will not be an organisational process, rather a value co-creation process with customers and business allies in the rising experience economy [5].

\subsection{Rewarding Mechanisms}

Co-creation may tap into the intellectual capital of customers; therefore companies should acknowledge their consumers and incentive them for their contributions, especially for those ideas that represent real economic benefits for the organisation. Companies should also keep in mind that rewarding consumers (e.g. free trials, samples of products, prizes for the best customer innovations) is one of the best mechanisms to keep alive proactive behaviour during the value co-creation processes [22] [23].

Considering the above, if companies want to keep the ideas flowing from their customers and their communities, they should show pre-emptive generosity, taking into consideration the consumers' contributions that are more significant for value cocreation, and reward customers by sharing intellectual property with them when they engage in a value co-creation processes (e.g. co-development, co-design, etc.) or simply share royalties in exchange for their ideas [22] [23].

Ultimately, a value co-creation process moves along to a joint product development, where individual contributions to value co-creation become more difficult to determine, and for this reason, ownership of Intellectual Property (IP) becomes quite troublesome. Therefore, new research in IP management is required, especially in the field of customer involvement in value co-creation processes.

The result of the following set of guidelines described by the reference framework presented in this paper represents the first steps towards formalizing a methodology for the creation of experience-centric networks (see Fig. 2). 


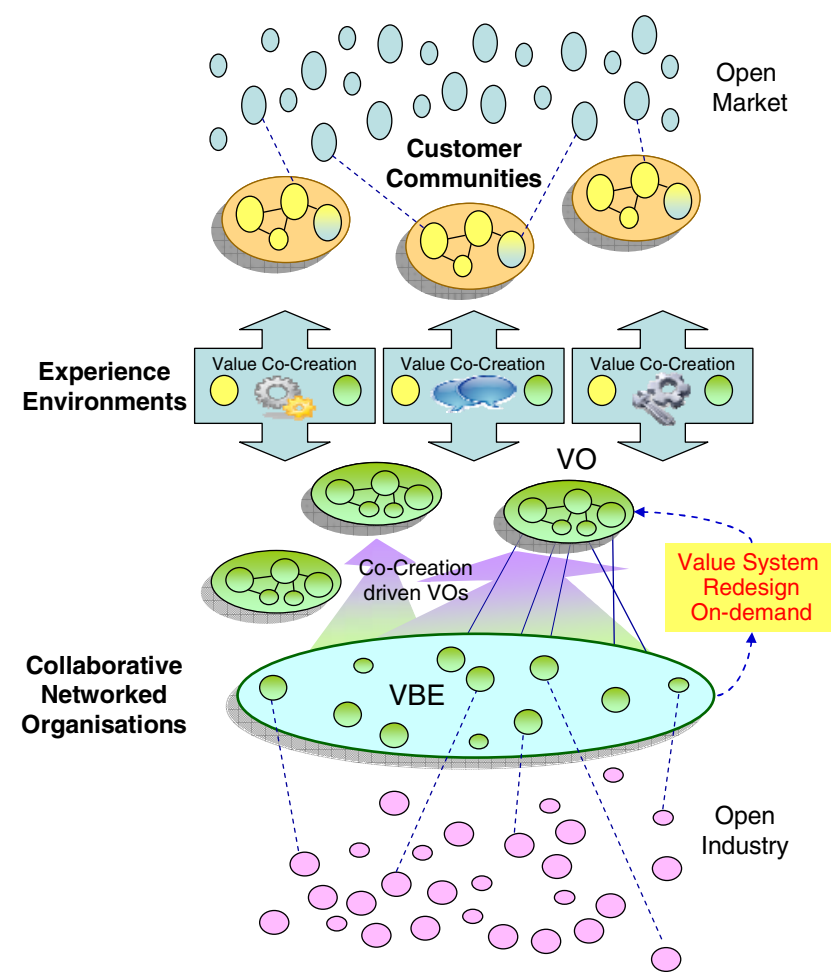

Fig. 2. Experience-Centric Network Scenario

\section{Conclusions}

Value co-creation has shift the traditional idea of value creation, in where customers were seen as "destroying the value which organisations create for them", while in alternative the new value creation paradigm views customers "actively co-creating and re-creating value with organisations" [24]. Thus, all these changes are setting the stage for an expanded role for customers, in new experience environments, where customers are no longer passive recipients of products; instead customers are now active partners co-creating value with organisations.

Furthermore, the current trend of customer involvement will continue maturing in the following years, changing the customer role from a pure consumer of products to a partner in the value creation process, and as a result organisational structures and business models will migrate into new strategic alliances and collaborative models based-on open business models that will support the creation and operation of adequate collaboration e-platforms for value co-creation. A lot of research remains to be done towards closing the interaction gaps that represent big obstacles for an effective involvement of customers in communities and organisations in collaborative networks to create the synergy necessary to integrate both sides in experience-centric networks capable of satisfying customers' needs, wants, and aspirations, and at the same time organisations' revenue goals. 
As a conclusion, mass-customization, personalization, customer integration and open innovation trends will continue as early-strategies of value co-creation between organisations and customers, but as mentioned by Prahalad \& Ramaswamy [5]: "The future will belong to those companies that continuously generate new knowledge from customers' experiences, and identify and enable new co-creation opportunities to support compelling experience environments".

Acknowledgments. The research presented in this document is a contribution for the ECOLEAD Project, funded by the European Community, FP6 IP 506958, for the "Rapid Product Realization for Developing Markets Using Emerging Technologies" Research Chair, ITESM, Campus Monterrey, and for the "Technological Innovation" Research Chair, ITESM, Campus Ciudad de México.

\section{References}

1. Camarinha-Matos, L.M., Afsarmanesh, H.: Collaborative Networks: Value Creation in a Knowledge Society. In: Wang, K., et al. (eds.) Knowledge Enterprise. IFIP, vol. 207, pp. 26-40. Springer, New York (2006)

2. Piller, F., Schubert, P., Koch, M., Möslein, K.: Overcoming Mass Confusion: Collaborative Customer Co-Design in Online Communities. Journal of Computer-Mediated Communication 10(4) (2005)

3. Subramani, M.R., Rajagopalan, B.: Knowledge-Sharing and Influence in Online Social Networks via Viral Marketing. Communications of the ACM 46(12), 300-307 (2003)

4. Andersen, H.: Relationship Marketing and Brand Involvement of Professionals Through Web-enhanced Brand Communities. Journal of Industrial Marketing Management 34(1), 39-51 (2005)

5. Prahalad, C.K., Ramaswamy, V.: The Future of Competition: Co-creating Unique Value with Customers. Harvard Business School Press (2004)

6. Normann, R., Ramirez, R.: From Value Chain to Value Constellation: Designing Interactive Strategy. Harvard Business Review 71(4), 65-77 (1993)

7. Ståhle, P., Laento, K.: Strategic Partnership: Key to Continuous Renewal. In: WSOY, Economy, Helsinki, p. 165 (2000)

8. Camarinha-Matos, L.M., Afsarmanesh, H.: A Framework for Virtual Organization Creation in a Breeding Environment. International Journal Annual Reviews in Control 31, 119135 (2007)

9. Curien, N., Fauchart, E., Laffond, G., Moreau, F.: Internet and Digital Economics: Principles, Methods and Applications. In: Trousseau, E., Curien, N. (eds.) Online Consumer Communities: Escaping the Tragedy of the Digital Commons, pp. 201-219. Cambridge University Press, Cambridge (2007)

10. Katzy, B., Obozinski, V.: Value System Redesign. ACM SIGROUP Bulletin 19(3), 48-50 (1998)

11. Tzu-Ying, C., Jen-Fan, L.: A Comparative Study of Online User Communities Involvement in Product Innovation and Development. In: 13th International Conference on Management of Technology (2004)

12. Manville, B.: Knowledge Networks - Innovation through Communities of Practices. In: Hildreth, P., Kimble, C. (eds.) Building Customer Communities of Practice for Business Value: Success Factors Profiled from Saba Software and Other Case Studies, pp. 106-123. Idea Group Publishing (2004) 
13. Communispace Corporation, Making Social Networking Work for Marketing: Communispace Shares 10 Best Practices for Online Customer Communities, in Press Releases by Swaysland, J. and Kelly, L. (2004)

14. Möller, K., Rajala, R., Westerlund, M.: Service Myopia? - A New Recipe for ClientProvider Value Creation. In: The Berkeley-Tekes Service Innovation Conference (2007)

15. Msanjila, S.S., Afsarmanesh, H.: Modelling Trust Relationships in Collaborative Networked Organizations. The International Journal of Technology Transfer and Commercialisation 6(1), 40-55 (2007)

16. Mezgár, I.: Trust Building for enhancing Collaboration in Virtual Organisations. In: Camarinha-Matos, L.M., Afsarmanesh, H., Ollus, M. (eds.) Network-Centric Collaboration and Supporting Frameworks. IFIP, vol. 224, pp. 173-180. Springer, Boston (2006)

17. Jarvenpaa, S.L., Knoll, K., Leidner, D.E.: Is there any body out there? Antecedents of Trust in Global Virtual Teams. Journal of Management Information Systems 14(4), 29-64 (1998)

18. Ramaswamy, V.: Co-Creating Experiences of Value with Customers: Building Experience Co-Creation Platforms Enhances Value Creation and Fosters Innovation. Platforms for Enterprise Agility: Business Innovation through Technology, SETLabs Briefings 4(1), 25-36 (2006)

19. Thomke, S., Von Hippel, E.: Customers as Innovators: A New Way to Create Value. Harvard Business Review 80(4) (2002)

20. eGain, Delivering Innovative Customer Interaction Hub Solutions, in Customer Inter@ction Solutions Magazine (2007)

21. Ramaswamy, V., Gouillart, F.: The Process of Experience Co-Creation. In: Experience Co-creation Partnership Workshop Proceedings (2007)

22. Trendwatching - Global Consumer Trends, Ideas and Insight, Customer-Made, in Trends Reports (2006)

23. Von Hippel, E.: Democratizing Innovation: The Evolving Phenomena of User Innovation. Journal für Betriebswirtschaft 55, 63-78 (2005)

24. Ramirez, R.: Value Co-Production: Intellectual Origins and Implications for Practice and Research. Strategic Management Journal 20(1), 49-65 (1999) 